\title{
Effects of Collectors and Frothers on Copper and Molybdenum Coarse Particle Recoveries-A Statistical Approach
}

\author{
Tony Di Feo*, Rolando Lastra \\ Natural Resources Canada, Canmet Mining, Ottawa, Canada \\ Email: *tony.difeo@canada.ca
}

How to cite this paper: Feo, T.D. and Lastra, R. (2019) Effects of Collectors and Frothers on Copper and Molybdenum Coarse Particle Recoveries-A Statistical Approach. Journal of Minerals and Materials Characterization and Engineering, 7, 117-136.

https://doi.org/10.4236/jmmce.2019.73009

Received: February 19, 2019

Accepted: May 11, 2019

Published: May 14, 2019

Copyright $\odot 2019$ by author(s) and Scientific Research Publishing Inc. This work is licensed under the Creative Commons Attribution International License (CC BY 4.0).

http://creativecommons.org/licenses/by/4.0/

(c) (i) Open Access

\begin{abstract}
Typically, coarse dense mineral particles greater than $150 \mu \mathrm{m}$ are difficult to float, and the recovery decreases progressively. Various physical parameters can be manipulated in an attempt to increase the recovery. These physical parameters are the following: liberation, turbulence in the flotation cell, $\mathrm{pH}$, collector, frother type and dosage. The testwork discussed in this paper was performed for a copper-molybdenum operation that is experiencing coarse particle $(>150 \mu \mathrm{m})$ losses in the tails. This operation uses Diesel No. 2 fuel and sodium ethyl xanthate for molybdenum and copper flotation, respectively and X-133 frother. In an attempt to increase coarse particle recovery, stronger collectors (potassium amyl xanthate, Aero 249 and Aero 3501) and frothers (FrothPro 618, FrothPro 630 and FrothPro 706) were used. The analysis was performed using the Analysis of Variance (ANOVA) approach. The conditions required by the ANOVA method were met. The results showed that the collector potassium amyl xanthate (PAX) with frothers X-133 and FrothPro 630 resulted in approximately $3 \%$ increase in copper rougher recovery relative to the baseline (sodium ethyl xanthate and X-133). The collectors and frothers did not have a significant effect on molybdenum recovery within the dosage limits investigated.
\end{abstract}

\section{Keywords}

Mineral Particles, Physical Parameters, , Coarse Particles, Flotation

\section{Introduction}

The maximum recovery of particles in flotation is typically in the 20 to $150 \mu \mathrm{m}$ size range [1]. Outside this range, the particle recovery decreases progressively. There are a few factors that affect the flotation of coarse particles. The environ- 
ment in the flotation cell has a significant impact on the detachment of coarse particles from the bubbles and environments that are more quiescent favour coarse particle flotation [2]. The particles are detached from bubbles due to bubble oscillations, gravitational forces and turbulent forces in agitated flotation machines [3]. In addition, collector dosage rate and hydrophobicity affect coarse particles flotation [4] [5] and [6]. In general, higher level of hydrophobicity is required for coarse particle flotation. Fosu et al., 2015 [3] determined the detachment force of sphalerite particles from air bubbles. The size range used was $150-300 \mu \mathrm{m}$ and $300-600 \mu \mathrm{m}$ with different degrees of liberation. The collectors used in the experimentation were sodium isopropyl xanthate (SIPX) and potassium amyl xanthate (PAX) at different concentrations. These investigators found that particles conditioned with PAX required a higher force to be detached from bubbles than particles conditioned with SIPX.

The froth phase is an extremely important part of flotation. If the froth phase is unstable, then the flotation performance, recovery and grade, will be poor. Froth stability is strongly influenced by particle size and hydrophobicity [6]. Thus, in the flotation process, more than one type of frother may have to be used to recover the fine and coarse particles. Ata and Jameson, 2013 [7] investigated the recovery of coarse particles in various heights in the froth. They found that the coarse particle recovery decreased when the particles were added at the pulp-froth interface. They concluded that coarse particles are poorly recovered in conventional flotation cells.

To obtain higher coarse particle flotation in conventional flotation cells, higher hydrophobicity (more collector and/or stronger collector) is needed to increase the detachment forces required to pull the particle from the air bubble [8] and the froth has to be capable of supporting the coarse particles.

The testwork presented in this paper was done for a copper-molybdenum operation that is experiencing fine particles $(<20 \mu \mathrm{m})$ and coarse particle losses $(>150 \mu \mathrm{m})$. The objective is to increase the coarse particle recovery by using stronger collectors (increasing surface hydrophobicity) and stronger frothers (higher glycol concentration). The collectors tested are the following: sodium ethyl xanthate (baseline), potassium amyl xanthate, Aero 3501 and Aero 249. The frothers used are the following: X-133 (baseline), FrothPro 618, FrothPro 630 and FrothPro 706. The FrothPro 618, FrothPro 630 and FrothPro 706 frothers have higher concentrations of glycol relative to the X-133 frother.

The paper also presents a strict statistical approach to assess the results. The ANOVA statistical approach was used to determine the significance of the results.

\section{Experimental}

The ore was crushed to $2000 \mu \mathrm{m}$ ( -10 mesh), blended and split into $1 \mathrm{~kg}$ charges which were used in this testwork (grind curve determination and flotation).

Table 1 provides the assays for the ore received. Table 1 also gives the relative standard deviations (RSD), defined as the standard deviation divided by the av- 
erage. The RSD is less than 5\% for copper, iron and total sulphur (LECO Sulphur), the low values of RSD indicate that the ore sample is well blended. The RSD of molybdenum was slightly higher than $5 \%$.

A grind curve to achieve a $\mathrm{P}_{80}$ of $265 \mu \mathrm{m}$ was developed using a lab scale mill. The grinding was done at $60 \%$ solids by weight, lime was added to the mill to achieve a $\mathrm{pH}$ of 10.3 , and $20.6 \mu \mathrm{L}$ of No 2 Diesel fuel was added to the mill. The dosage of Diesel No 2 fuel in the mill $(20.6 \mu \mathrm{L})$ was kept constant throughout the testwork.

A lab scale mill (internal length of $40.64 \mathrm{~cm}$ and internal diameter of 20.32 $\mathrm{cm}$ ) with $\sim 14 \mathrm{~kg}$ of mild steel balls of assorted sizes (Table 2) was used for grinding the ore ( $1 \mathrm{~kg}$ charge). The time required to achieve the grind size target was 4 minutes.

The flotation tests were performed using a Denver laboratory machine with a 2 litre cell. The flotation testwork was based on the procedure indicated by the concentrator that provided the ore for testing. In all the flotation tests, concentrates 1, 2, 3 and 4 were collected for 45 seconds, 1.25 minutes, 3.0 minutes and 2.0 minutes, respectively for a total of 7 minutes. $0.648 \mathrm{~g} / \mathrm{t}(0.0360 \mathrm{lb} / \mathrm{st})$ of collector and $0.081 \mathrm{~g} / \mathrm{t}(0.0045 \mathrm{lb} / \mathrm{st})$ of X-133 frother were added at the beginning of the flotation test. In all of the flotation tests X-133 was added prior to concentrate 1 . Whereas an additional $0.0405 \mathrm{~g} / \mathrm{t}(0.0023 \mathrm{lb} / \mathrm{st})$ of frother was added at the beginning of concentrates 3 and 4 . The frother type added prior to concentrates 3 and 4 changed depending on the test. The $\mathrm{pH}$ was maintained at 10.3 using lime throughout the test. Table 3 illustrates the flotation schedule for the testwork.

The collectors used were the following: sodium ethyl xanthate (SEX), potassium amyl xanthate (PAX), Aero 3501 and Aero 249. The frothers used were the following: X-133, FrothPro 618, FrothPro 630 and FrothPro 706. All the tests were duplicated for a total of 32 flotation tests. Table 4 shows the experimental plan with randomized tests.

Table 1. External reference distribution.

\begin{tabular}{ccccc}
\hline & Copper & Iron & Molybdenum & Total Sulphur \\
\hline Average (\%) & 0.275 & 1.81 & 0.0136 & 0.70 \\
St. Deviation & $2.95 \times 10^{-3}$ & $4.34 \times 10^{-2}$ & $1.11 \times 10^{-3}$ & $1.19 \times 10^{-16}$ \\
RSD (\%) & 1.07 & 2.40 & 8.16 & $1.70 \times 10^{-14}$ \\
\hline
\end{tabular}

Table 2. Ball distribution for laboratory testwork.

\begin{tabular}{ccc}
\hline Ball Diameter (inches) & \# of Balls & Ball Distribution (\%) \\
\hline 1.50 & 16 & 5.32 \\
1.25 & 25 & 8.38 \\
1.00 & 38 & 12.78 \\
0.75 & 87 & 29.35 \\
0.625 & 131 & 44.17 \\
\hline
\end{tabular}


Table 3. Flotation schedule*.

\begin{tabular}{cccccc}
\hline Reagent & $\begin{array}{c}\text { Dosage } \\
(\mathrm{g} / \mathrm{t})\end{array}$ & $\begin{array}{c}\text { Conditioning Time } \\
\text { (Minutes) }\end{array}$ & Stage & $\begin{array}{c}\text { Flotation Time } \\
\text { (Minutes) }\end{array}$ & $\begin{array}{c}\text { Total Flotation } \\
\text { Time (Minutes) }\end{array}$ \\
\hline Collector & 0.648 & 1.0 & Conc 1 & 0.75 & 0.75 \\
$\mathrm{X}-133$ & 0.081 & 0.5 & Conc 2 & 1.25 & 2.0 \\
Frother & 0.0405 & 1.0 & Conc 3 & 3.0 & 5.0 \\
& & & & & \\
Frother & 0.0405 & 1.0 & Conc 4 & 2.0 & 7.0 \\
\hline
\end{tabular}

${ }^{*} \mathrm{pH}$ of 10.3 was maintained using lime throughout the test.

Table 4. Randomized flotation tests.

\begin{tabular}{|c|c|c|c|}
\hline Collector & Frother - Concentrate 1 & Frother - Concentrate 3 & Frother - Concentrate 4 \\
\hline PAX & $\mathrm{X}-133$ & $\mathrm{X}-133$ & $\mathrm{X}-133$ \\
\hline Aero 3501 & $\mathrm{X}-133$ & $\mathrm{X}-133$ & $\mathrm{X}-133$ \\
\hline Aero 249 & $\mathrm{X}-133$ & X-133/FrothPro 618 & X-133/FrothPro 618 \\
\hline Aero 249 & $\mathrm{X}-133$ & X-133/FrothPro 706 & X-133/FrothPro 706 \\
\hline PAX & $\mathrm{X}-133$ & X-133/FrothPro 630 & X-133/FrothPro 630 \\
\hline Aero 3501 & $\mathrm{X}-133$ & $\mathrm{X}-133$ & $\mathrm{X}-133$ \\
\hline SEX & $\mathrm{X}-133$ & $\mathrm{X}-133$ & $\mathrm{X}-133$ \\
\hline Aero 249 & $\mathrm{X}-133$ & X-133/FrothPro 618 & X-133/FrothPro 618 \\
\hline PAX & $\mathrm{X}-133$ & X-133/FrothPro 630 & X-133/FrothPro 630 \\
\hline Aero 249 & $\mathrm{X}-133$ & $\mathrm{X}-133$ & $\mathrm{X}-133$ \\
\hline SEX & $\mathrm{X}-133$ & X-133/FrothPro 706 & X-133/FrothPro 706 \\
\hline Aero 3501 & $\mathrm{X}-133$ & X-133/FrothPro 706 & X-133/FrothPro 706 \\
\hline Aero 3501 & $\mathrm{X}-133$ & X-133/FrothPro 618 & X-133/FrothPro 618 \\
\hline Aero 249 & $\mathrm{X}-133$ & $\mathrm{X}-133$ & $\mathrm{X}-133$ \\
\hline SEX & $\mathrm{X}-133$ & X-133/FrothPro 618 & X-133/FrothPro 618 \\
\hline PAX & $\mathrm{X}-133$ & X-133/FrothPro 706 & X-133/FrothPro 706 \\
\hline Aero 3501 & $\mathrm{X}-133$ & X-133/FrothPro 630 & X-133/FrothPro 630 \\
\hline SEX & $\mathrm{X}-133$ & X-133/FrothPro 630 & X-133/FrothPro 630 \\
\hline Aero 249 & $\mathrm{X}-133$ & X-133/FrothPro 706 & X-133/FrothPro 706 \\
\hline PAX & $\mathrm{X}-133$ & X-133/FrothPro 706 & X-133/FrothPro 706 \\
\hline Aero 3501 & $\mathrm{X}-133$ & X-133/FrothPro 630 & X-133/FrothPro 630 \\
\hline SEX & $\mathrm{X}-133$ & X-133/FrothPro 618 & X-133/FrothPro 618 \\
\hline Aero 3501 & $\mathrm{X}-133$ & X-133/FrothPro 706 & X-133/FrothPro 706 \\
\hline Aero 249 & $\mathrm{X}-133$ & X-133/FrothPro 630 & X-133/FrothPro 630 \\
\hline SEX & $\mathrm{X}-133$ & X-133/FrothPro 706 & X-133/FrothPro 706 \\
\hline
\end{tabular}




\begin{tabular}{cccc} 
Continued & & & \\
\hline PAX & X-133 & X-133/FrothPro 618 & X-133/FrothPro 618 \\
Aero 249 & X-133 & X-133/FrothPro 630 & X-133/FrothPro 630 \\
SEX & X-133 & X-133/FrothPro 630 & X-133/FrothPro 630 \\
Aero 3501 & X-133 & X-133/FrothPro 618 & X-133/FrothPro 618 \\
PAX & X-133 & X-133 & X-133 \\
PAX & X-133 & X-133/FrothPro 618 & X-133/FrothPro 618 \\
SEX & X-133 & X-133 & X-133 \\
\hline
\end{tabular}

The flotation products were dried at $\sim 35^{\circ} \mathrm{C}$. The concentrates were weighed and pulverized for assaying. The tails were weighed and passed through a 300 $\mu \mathrm{m}$ screen to break-up any clumps. Then, they were homogenized for 1 hour using a V-blender and split into 8 sub-samples using a laboratory spin riffler. Two tails sub-samples were pulverized and sent for assaying. Also, these tails sub-samples were used for mineralogy if necessary.

The mineralogical characterization was done using an automated scanning electron microscope (TESCAN Integrated Mineral Analyzer-TIMA). The feed and selected flotation tailings were sieved into size fractions. Polished sections of $30 \mathrm{~mm}$ diameter were prepared from each size fraction. Two polished sections were prepared from each size fraction coarser than $150 \mu \mathrm{m}$. This was done to analyze more particles. For the size fractions $150 \mu \mathrm{m}$ and finer only one polished section was prepared. The TIMA run was done at $25 \mathrm{kV}$ of acceleration voltage and $5 \mathrm{nA}$ of beam current analyzing spots on the particles every $5 \mu \mathrm{m}$ (high resolution map mode).

\section{Results}

\subsection{Mineralogy}

The mineralogical characterization was done for each size fraction of the feed. This is known as a size-by-size mineralogical characterization. This approach yields a large amount of data. 3D plots allow illustrating large amount of data. Figure 1 is a $3 \mathrm{D}$ plot that gives the mineral quantities in each size fraction of the feed. The $\mathrm{Y}$-axis gives the weight percent of the mineral indicated in the $\mathrm{X}$-axis that is in the size fraction in the Z-axis (also shown as the bar colour). In a very simplified way, the mineralogy indicates that the main gangue minerals in the feed are quartz, orthoclase, albite, muscovite, biotite and pyrite.

Figure 2 is a $3 \mathrm{D}$ plot that shows the chalcopyrite liberation. The $\mathrm{Y}$-axis gives the cumulative percentage of the chalcopyrite at each liberation class indicated in the $\mathrm{X}$-axis, that is in the size fraction in the Z-axis (also shown as the bar colour). Figure 2 shows that at sizes less than $300 \mu \mathrm{m}$ (212 to $38 \mu \mathrm{m})$ the chalcopyrite was well liberated. However, at sizes $300 \mu \mathrm{m}$ and higher, the liberation was rather poor ( $<50 \%$ liberation).

Figure 3 is a $3 \mathrm{D}$ plot that illustrates the molybdenum liberation in the feed. 


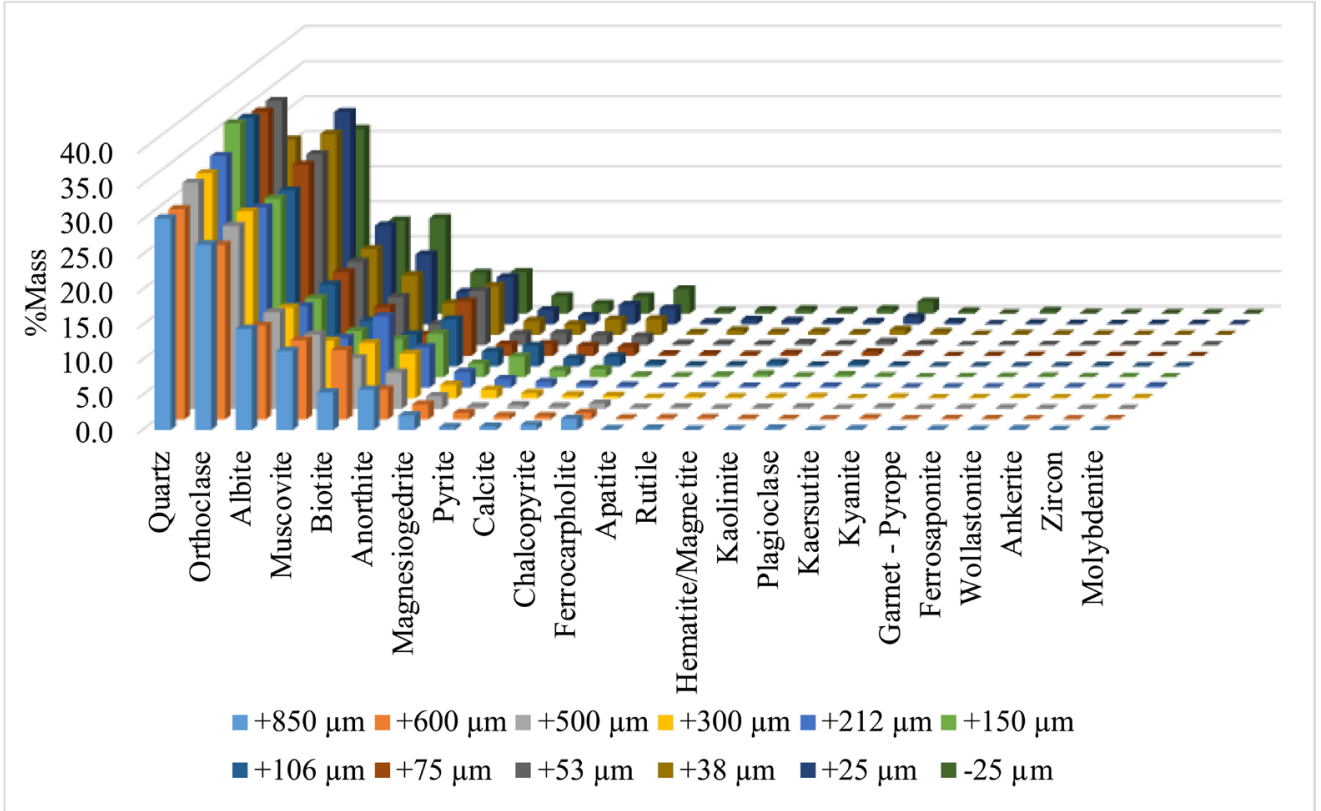

Figure 1. Feed mineralogy.

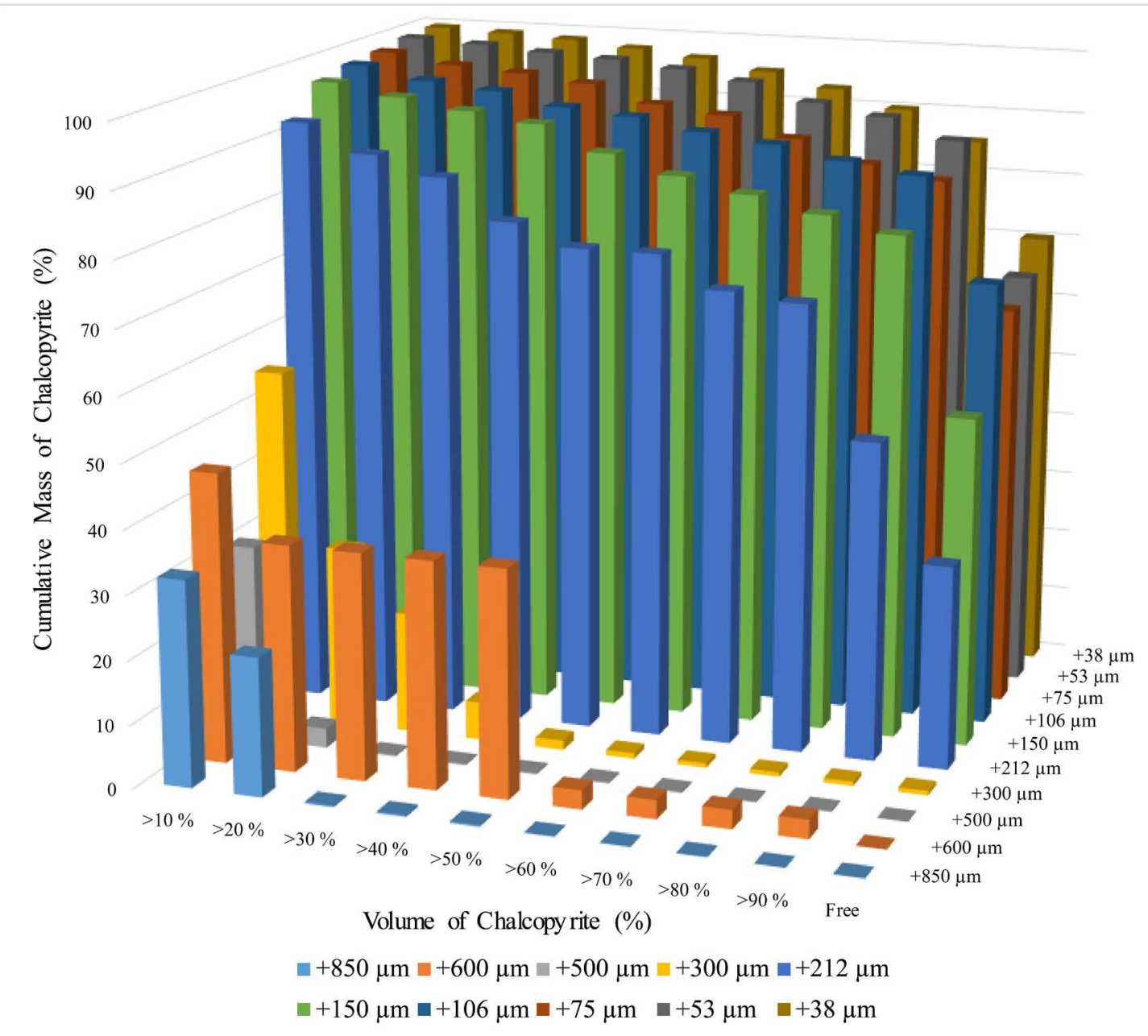

Figure 2. Chalcopyrite liberation. 


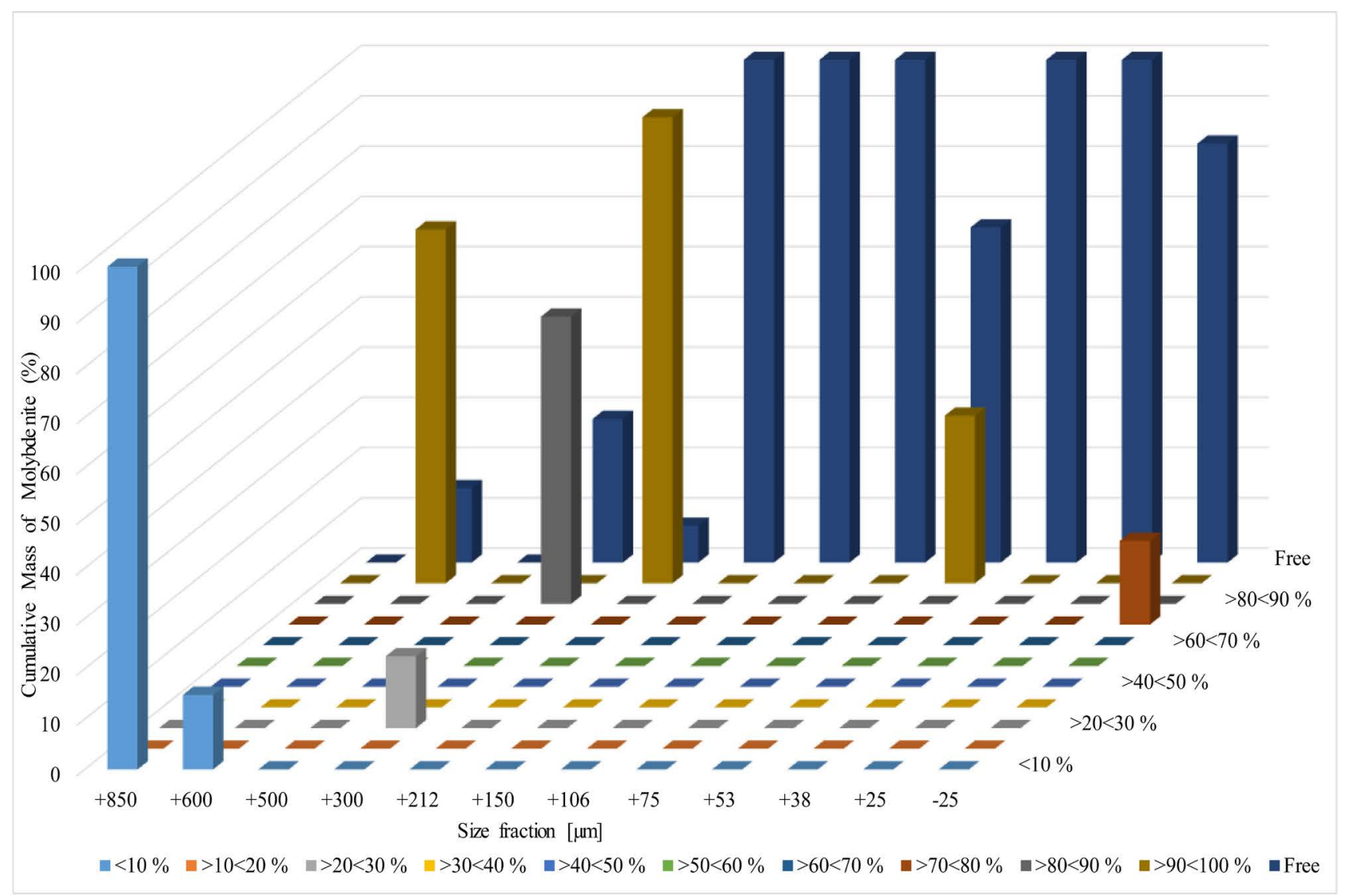

Figure 3. Molybdenum liberation in the feed.

The $\mathrm{Y}$-axis gives the cumulative percentage of the molybdenite that is in the size fraction indicated in the $\mathrm{X}$-axis at several liberation classes indicated by the $\mathrm{Z}$-axis (also shown as the bar colour). Figure 3 is sparsely populated because the data for molybdenite is also sparse. Molybdenite in the feed is in much lower proportions than chalcopyrite. Figure 4 indicates that the chalcopyrite mass percent in the size fractions is between $0.5 \%$ to $3.5 \%$. Whereas Figure 5 indicates that molybdenite mass percent is between $0.01 \%$ to $0.2 \%$. Therefore, the particles bearing molybdenite are very few. To have reliable numbers on the liberation of molybdenite it would be required to run about 10 polished sections of each size fraction to accumulate more data. This level of effort was outside the scope of this research. Due to the low proportion of molybdenite in the feed and the number of polished sections analyzed, the measured liberation of the molybdenite indicated in Figure 3 should be considered an estimate. Particles with more than $80 \%$ molybdenite can be considered liberated for flotation concentration. Figure 3 indicates that the molybdenite is mostly liberated in the feed size fractions $300 \mu \mathrm{m}$ and finer, whereas, the molybdenite in the feed size coarser than $300 \mu \mathrm{m}$ is primarily not liberated. 


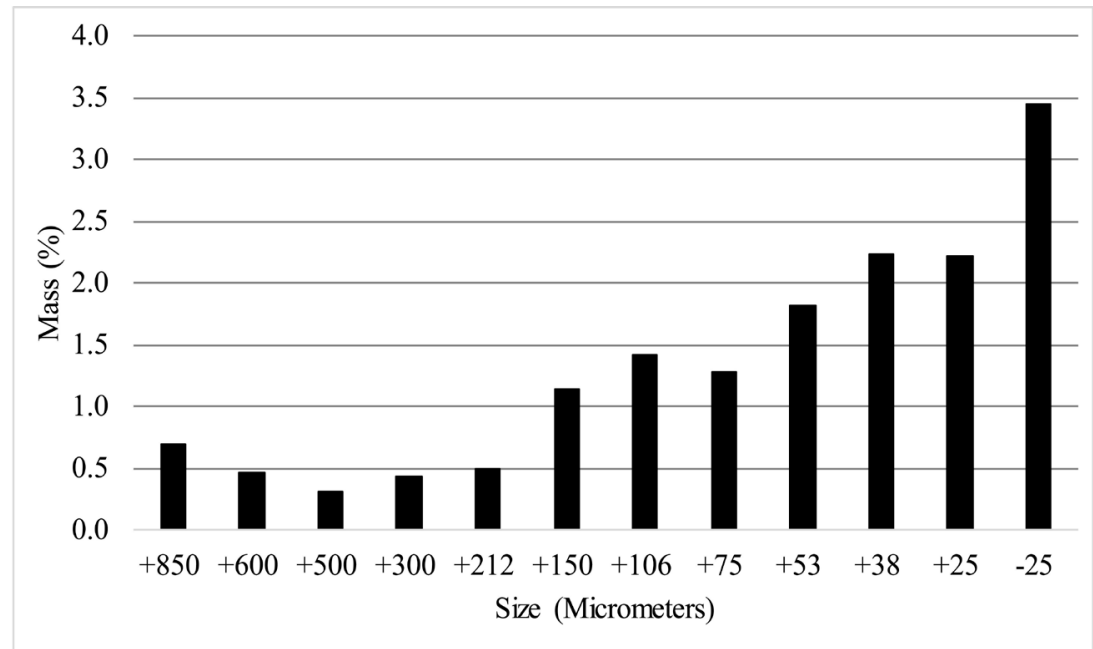

Figure 4. Chalcopyrite feed size-by-size mass (\%).

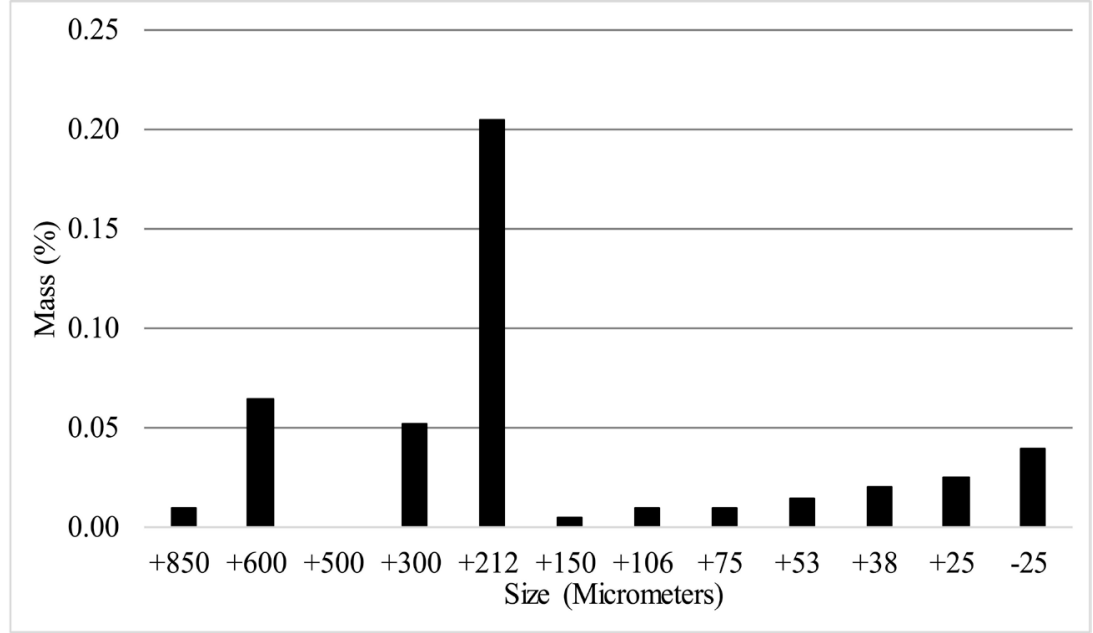

Figure 5. Molybdenum feed size-by-size mass (\%).

\subsection{Flotation Tests}

Table 5 and Table 6 illustrate the results of the replicated 16 conditions (32 flotation tests). The condition SEX \& X-133 is the baseline.

Table 5. Results for copper recovery (\%)

\begin{tabular}{ccccc}
\hline \multirow{2}{*}{ Collector } & X-133 & X-133/FrothPro & X-133/FrothPro & X-133/FrothPro \\
& & 618 & 630 & 706 \\
\hline \multirow{2}{*}{ SEX } & 82.48 & 79.90 & 84.13 & 83.19 \\
& 82.42 & 80.20 & 85.59 & 81.05 \\
PAX & 82.02 & 80.19 & 85.16 & 86.29 \\
\multirow{2}{*}{ Aero 3501 } & 81.54 & 85.60 & 86.63 & 84.57 \\
& 80.99 & 82.14 & 83.30 & 81.36 \\
Aero 249 & 83.34 & 82.94 & 79.63 & 81.20 \\
& 83.42 & 80.44 & 82.46 & 82.09 \\
\hline
\end{tabular}


Table 6. Results for molybdenum recovery (\%).

\begin{tabular}{ccccc}
\hline \multirow{2}{*}{ Collector } & X-133 & $\begin{array}{c}\text { X-133/FrothPro } \\
\text { X-133/FrothPro }\end{array}$ & $\begin{array}{c}\text { X-133/FrothPro } \\
\text { SEX }\end{array}$ \\
\multirow{2}{*}{ PAX } & 71.36 & 74.21 & $\mathbf{6 3 0}$ & $\mathbf{7 0 6}$ \\
\hline \multirow{2}{*}{ Aero 3501 } & 65.05 & 63.77 & 73.14 & 79.62 \\
& 73.10 & 81.28 & 77.07 & 75.44 \\
\multirow{2}{*}{ Aero 249 } & 70.43 & 73.62 & 76.42 & 68.84 \\
& 73.46 & 73.32 & 79.15 & 77.16 \\
& 75.19 & 76.40 & 65.29 & 74.73 \\
\hline
\end{tabular}

\subsection{Theory}

The ANOVA analysis is used by experimenters in various fields of research to test the effect of dependent variables on independent variables [9] and [10].

A two variable ANOVA analysis was performed. The theory is presented below [11].

$$
\begin{gathered}
\mathrm{SS}_{\text {collector }}=\left(\frac{1}{b n}\right) \sum_{i=1}^{a} y_{i . .}^{2}-\left(\frac{y_{\ldots}^{2}}{a b n}\right) \\
\mathrm{SS}_{\text {frother }}=\left(\frac{1}{a n}\right) \sum_{j=1}^{b} y_{. j .}^{2}-\left(\frac{y_{\ldots .}^{2}}{a b n}\right)
\end{gathered}
$$

where

$\mathrm{SS}_{\text {collector }}$ is the sum of squares for the collectors

$\mathrm{SS}_{\text {frother }}$ is the sum of squares for the frothers

$b$ is the number of frothers used in the testwork

$a$ is the number of collectors used in the testwork

$n$ is the number of replicates (in this testwork $n=2$ )

$y_{i .}$ is the total of the observations for collector $i$

$y_{j . j}$ is the total of the observations for frother $j$

$y$... represents the grand total of all observations

$$
\mathrm{SS}_{\text {total }}=\sum_{i=1}^{a} \sum_{j=1}^{b} \sum_{k=1}^{n} y_{i j k}^{2}-\frac{y_{\ldots}^{2}}{a b n}
$$

where

$\mathrm{SS}_{\text {total }}$ is the total sum of squares

$y_{i j k}$ is the observation $i j k$. This represents each observation for every collector $i$ and frother $j$.

$$
\begin{gathered}
\mathrm{SS}_{\text {interaction }}=\frac{1}{n} \sum_{i=1}^{q} \sum_{j=1}^{b} y_{i j .}^{2}-\frac{y_{\ldots}^{2}}{a b n}-\mathrm{SS}_{\text {collector }}-\mathrm{SS}_{\text {frother }} \\
\mathrm{SS}_{\text {error }}=\mathrm{SS}_{\text {total }}-\mathrm{SS}_{\text {collector }}-\mathrm{SS}_{\text {frother }}-\mathrm{SS}_{\text {interaction }}
\end{gathered}
$$

$y_{i j}$ is the sum of the observations of collector $i$ and frother $j$ or the sum of the replicates for collector $i$ and frother $j$. The mean square is the sum of square divided by the degrees of freedom. 


$$
\begin{gathered}
\mathrm{MS}_{\text {collector }}=\frac{\mathrm{SS}_{\text {collector }}}{a-1} \\
\mathrm{MS}_{\text {frother }}=\frac{\mathrm{SS}_{\text {frother }}}{b-1} \\
\mathrm{MS}_{\text {interaction }}=\frac{\mathrm{SS}_{\text {interaction }}}{(a-1)(b-1)} \\
\mathrm{MS}_{\text {error }}=\frac{\mathrm{SS}_{\text {error }}}{a b(n-1)}
\end{gathered}
$$

where

$\mathrm{MS}_{\text {collector }}$ is the mean square of the collectors

$\mathrm{MS}_{\text {frother }}$ is the mean square of the frothers

$\mathrm{MS}_{\text {interaction }}$ is the mean square of the interaction between the collectors and frothers

$\mathrm{MS}_{\text {error }}$ is the mean square of the error

For the collectors the $\mathrm{F}_{\mathrm{o}}$ is defined as:

$$
\mathrm{F}_{\mathrm{o}}=\frac{\mathrm{MS}_{\text {collector }}}{\mathrm{MS}_{\text {error }}}
$$

For the frothers the $\mathrm{F}_{\mathrm{o}}$ is defined as:

$$
\mathrm{F}_{\mathrm{o}}=\frac{\mathrm{MS}_{\text {frother }}}{\mathrm{MS}_{\text {error }}}
$$

For the interaction between the collectors and frothers the $\mathrm{F}_{\mathrm{o}}$ is defined as:

$$
\mathrm{F}_{\mathrm{o}}=\frac{\mathrm{MS}_{\text {interaction }}}{\mathrm{MS}_{\text {error }}}
$$

where

$\mathrm{F}_{\mathrm{o}}$ is a constant in the $\mathrm{f}$ distribution.

The $F_{o}$ value is compared to the critical $f$ value in the $f$ distribution. The $f$ critical value is obtained for a certain confidence level, the degrees of freedom for the variable in question and degrees of freedom of error. If the $F_{o}$ is greater than the $f$ critical, then the variable in question has a significant effect on the output (mineral recovery).

Table 7 shows the results of ANOVA analysis for copper recovery at the 95\% confidence level. Comparison of the $F_{o}$ versus the $f$ critical values indicate that

Table 7. Analysis of variance for copper recovery (\%).

\begin{tabular}{cccccccc}
\hline $\begin{array}{c}\text { Source of } \\
\text { Variation }\end{array}$ & $\begin{array}{c}\text { Sum of } \\
\text { Squares }\end{array}$ & $\begin{array}{c}\text { Degrees of } \\
\text { Freedom }\end{array}$ & $\begin{array}{c}\text { Mean } \\
\text { Square }\end{array}$ & Fo & $\mathbf{f}_{\text {critical }}$ & P value & Significant \\
\hline Collector & 34.18 & 3 & 11.39 & 3.98 & 3.24 & 0.027 & Yes \\
Frother & 15.80 & 3 & 5.27 & 1.84 & 3.24 & 0.181 & No \\
Interaction & 36.38 & 9 & 4.04 & 1.41 & 2.54 & 0.263 & No \\
Error & 45.82 & 16 & 2.86 & & & & \\
Total & 132.18 & 31 & & & & & \\
\hline
\end{tabular}


the collectors had a significant impact on copper recovery (5\% the effect was due to chance). The frothers and the interaction between the collectors and frothers were not significant. However, before accepting these results, we have to check for the normality of the residuals, constant variance as well as the relationship between the residuals versus run order of the tests and copper recovery versus run order. This analysis is discussed below.

The residuals of the tests have to be normally distributed. The residual is defined as follows:

$$
\begin{aligned}
\text { Residual }= & \text { Recovery of metal in test } \\
& - \text { average }(\text { recovery of test } 1 \text { and recovery of test } 2)
\end{aligned}
$$

Figure 6 illustrates the normality plot for the residuals for copper recovery. The residuals follow the normality line (dashed line), thus, this requirement is met. There are two points that are not located on the normality line (where arrows are pointing). To determine whether these are outliers, the standardized value of these residuals was calculated using the equation below [11].

$$
\text { Standardized value of residual }=\frac{\text { residual }}{\sqrt{\mathrm{MS}_{\text {error }}}}
$$

The standardized values of the points not on the normality line (indicated by the arrows) are 1.59. These are less than 2.0, thus they are not outliers [11].

Figure 7 illustrates the residuals versus copper recovery. This graphs shows

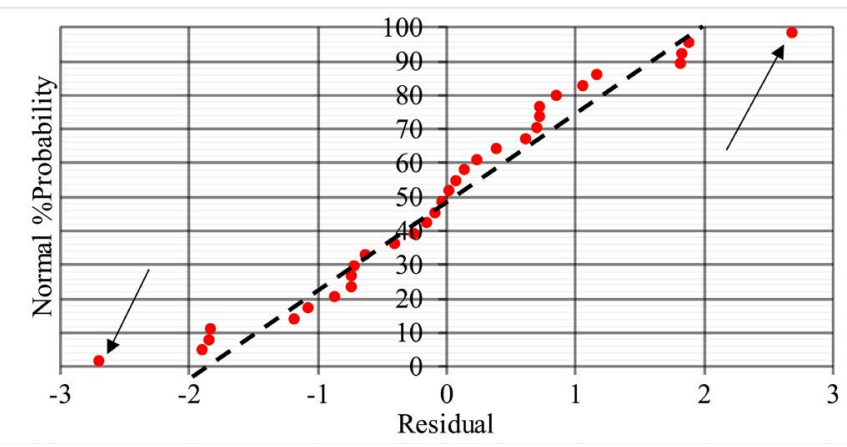

Figure 6. Normal\% probability versus residuals for copper recovery.

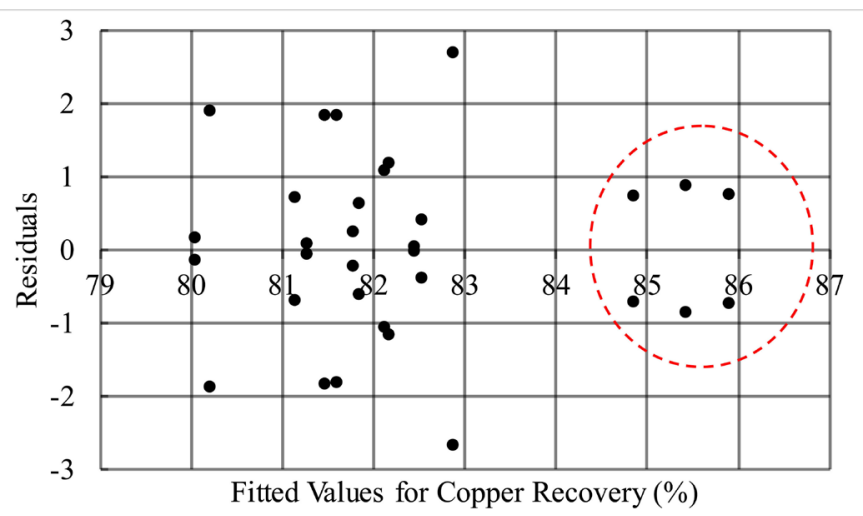

Figure 7. Residuals of copper recovery versus fitted values for copper recovery. 
whether the variance is constant. For copper recoveries below $\sim 83 \%$ the variance is constant, whereas, the variance for copper recoveries above $\sim 83 \%$ is lower (dotted red circle in Figure 7). Therefore, the Levene analysis was done to determine if the variance is indeed constant. This analysis is presented shortly.

Figure 8 and Figure 9 show the residuals versus frother type and residuals versus collector type for copper recovery, respectively. The variance in both graphs is fairly constant except for the residuals obtained with PAX and FrothPro 618. This test condition represents the points not located on the normality line in Figure 6.

To establish whether the variance is constant, the modified Levene test for equal variance was performed. This procedure is robust in departures from normality and can be calculated by the equation below [11]. Then the usual ANOVA analysis is done on the values obtained with the equation below.

$$
d_{i j}=\operatorname{Absolute}\left(y_{i j}-\text { median of treatment }\right)
$$

where

$d_{i j}$ represents the deviation from treatment median for observation $i j$

$y_{i j}$ represents the observation $i j$

ij represents variable $A$ at the $i^{\text {th }}$ and variable $B$ at the $f^{\text {th }}$ level

The null hypothesis is that the variance is constant, and the alternate hypothesis is the variance is not constant.

Table 8 illustrates the results of the deviations $\left(d_{i j}\right)$ for the modified Levene

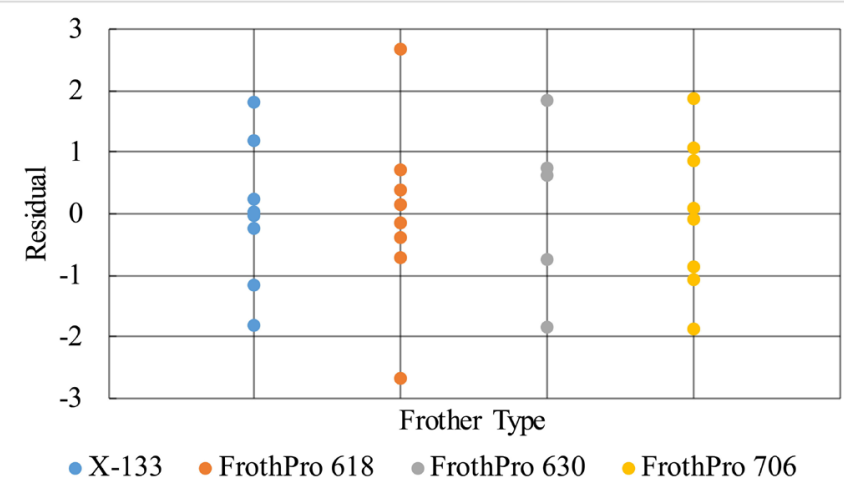

Figure 8. Residuals versus frother type-copper recovery.

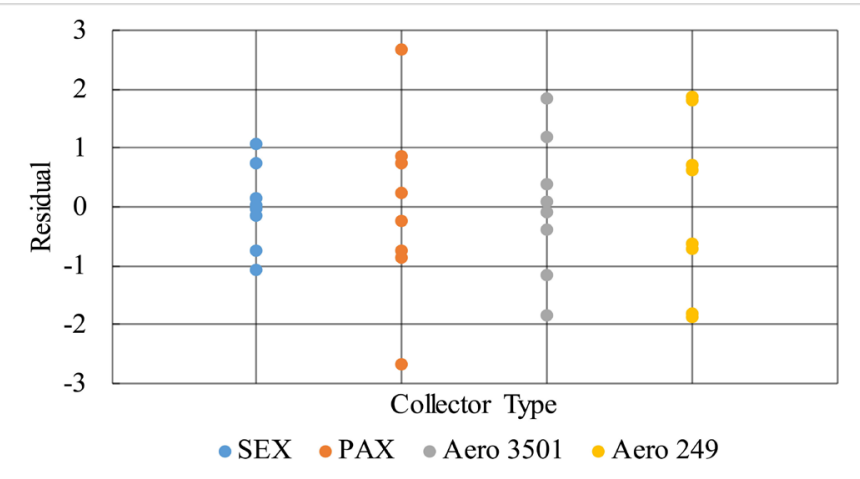

Figure 9. Residuals versus collector type-copper recovery. 
test of the observations for the collectors (copper recovery).

Table 9 illustrates the ANOVA analysis, 95\% confidence, on the deviations (collector) presented in Table 8. The $F_{o}$ is not greater than the $f$ critical, thus, the variance for the collectors is constant, or we do not reject the null hypothesis.

Table 10 illustrates the results of the deviations $\left(d_{i j}\right)$ for the modified Levene test of the observations for the frothers (copper recovery).

Table 11 illustrates the ANOVA analysis, 95\% confidence, on the deviations (frother) presented in Table 10 . The $F_{o}$ is not greater than the $f$ critical, thus, the variance for the frothers is constant, or we do not reject the null hypothesis.

Figure 10 and Figure 11 illustrate the copper recovery versus run order and

Table 8. Deviations $d_{i j}$ for the modified test-collectors.

\begin{tabular}{ccccc}
\hline Collector & $\mathrm{X}-133$ & $\begin{array}{c}\mathrm{X}-133 / \text { FrothPro } \\
\mathbf{6 1 8}\end{array}$ & $\begin{array}{c}\mathrm{X}-133 / \text { FrothPro } \\
\mathbf{6 3 0}\end{array}$ & $\begin{array}{c}\text { X-133/FrothPro } \\
\mathbf{7 0 6}\end{array}$ \\
\hline \multirow{2}{*}{ SEX } & 0.03 & 2.55 & 1.68 & 0.74 \\
& 0.03 & 2.25 & 3.14 & 1.40 \\
PAX & 2.85 & 4.68 & 0.30 & 1.43 \\
& 3.33 & 0.70 & 1.77 & 0.30 \\
Aero 3501 & 3.88 & 2.73 & 1.57 & 3.51 \\
& 1.59 & 1.19 & 2.12 & 0.55 \\
Aero 249 & 1.89 & 1.10 & 0.32 & 0.56 \\
& 1.76 & 0.32 & 0.93 & 3.22 \\
\hline
\end{tabular}

Table 9. Analysis of variance for collectors-copper recovery.

\begin{tabular}{cccccccc}
\hline $\begin{array}{c}\text { Source of } \\
\text { Variation }\end{array}$ & $\begin{array}{c}\text { Sum of } \\
\text { Squares }\end{array}$ & $\begin{array}{c}\text { Degrees of } \\
\text { Freedom }\end{array}$ & $\begin{array}{c}\text { Mean } \\
\text { Square }\end{array}$ & Fo & $\mathbf{f}_{\text {critical }}$ & P value & Significant \\
\hline Collector & 3.88 & 3 & 1.29 & 0.84 & 2.93 & 0.483 & No \\
Error & 42.92 & 28 & 1.53 & & & & \\
Total & 46.80 & & & & & \\
\hline
\end{tabular}

Table 10. Deviations $d_{i j}$ for the modified test-frothers.

\begin{tabular}{ccccc}
\hline Collector & X-133 & $\begin{array}{c}\text { X-133/FrothPro } \\
618\end{array}$ & $\begin{array}{c}\text { X-133/FrothPro } \\
630\end{array}$ & $\begin{array}{c}\text { X-133/FrothPro } \\
706\end{array}$ \\
\hline \multirow{2}{*}{ SEX } & 0.26 & 1.25 & 0.42 & 1.47 \\
& 0.20 & 0.95 & 1.88 & 0.68 \\
PAX & 0.20 & 0.96 & 1.45 & 4.57 \\
& 0.68 & 4.42 & 2.92 & 2.85 \\
Aero 3501 & 1.23 & 1.0 & 0.42 & 0.37 \\
& 1.12 & 1.80 & 4.09 & 0.53 \\
Aero 249 & 1.20 & 0.71 & 2.50 & 0.37 \\
& 2.44 & 0.71 & 1.26 & 3.41 \\
\hline
\end{tabular}


Table 11. Analysis of variance for frothers-copper recovery.

\begin{tabular}{cccccccc}
\hline $\begin{array}{c}\text { Source of } \\
\text { Variation }\end{array}$ & $\begin{array}{c}\text { Sum of } \\
\text { Squares }\end{array}$ & $\begin{array}{c}\text { Degrees of } \\
\text { Freedom }\end{array}$ & $\begin{array}{c}\text { Mean } \\
\text { Square }\end{array}$ & $F_{0}$ & $f_{\text {critical }}$ & P value & Significant \\
\hline Frother & 7.87 & 3 & 2.62 & 1.79 & 2.93 & 0.172 & No \\
Error & 40.96 & 28 & 1.46 & & & & \\
Total & $\mathbf{4 8 . 8 3}$ & & & & & & \\
\hline
\end{tabular}

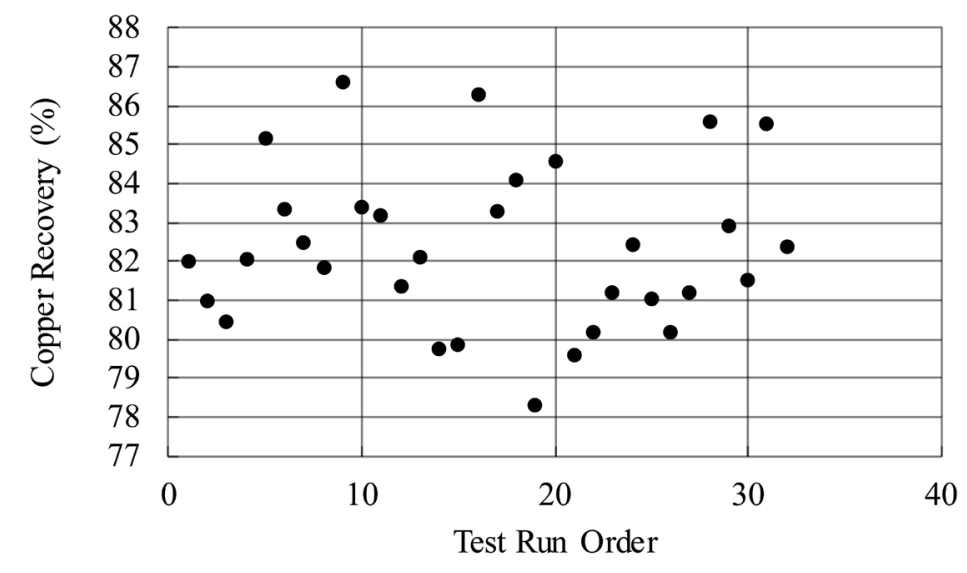

Figure 10. Copper recovery versus test run order.

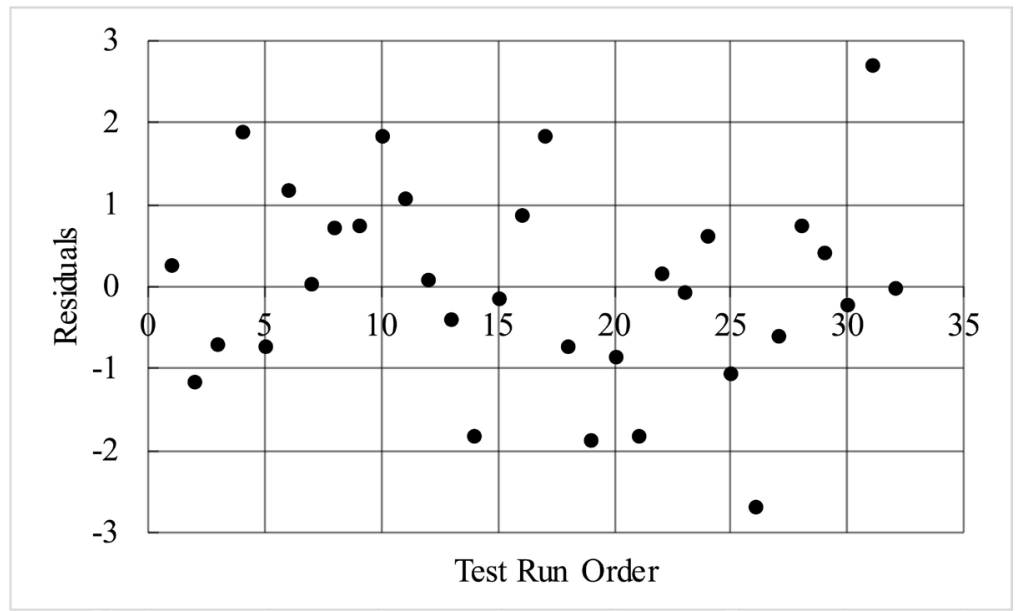

Figure 11. Residuals (copper recovery) versus test run order.

residuals versus run order, respectively. There should be no trends in these graphs. If there are trends, then something went wrong with the experiments or the results are biased. In both figures there is no trend in that data, which is acceptable.

All the conditions for the ANOVA were met for copper recovery, thus, conclusions can be made with high level of confidence regarding the effects of collectors and frothers on copper recovery.

As discussed, the collectors had a significant impact on copper recovery. However, in order to determine which collector(s) had a significant impact on 
copper recovery, the Fisher Least Significance Method analysis was used at the $90 \%$ and $95 \%$ confidence level.

The equation for the Fisher Least Significance Method is shown below [11].

$$
\mathrm{LSD}=t_{\frac{\alpha}{2}, d f} \sqrt{\frac{2 \mathrm{MS}_{\text {error }}}{n}}
$$

where

$t_{\frac{\alpha}{2}, d f}$ is the critical $t$ value from $t$ distribution at $100(1-\alpha)$ confidence with df degrees of freedom

$\mathrm{MS}_{\text {error }}$ is the mean square of error

$n$ is the number of replicates

LSD is the minimum difference between the observations required for a confidence at $100(1-\alpha)$

The Fisher Least Significance difference showed that the following conditions are significant at the $95 \%$ confidence level (copper recovery).

1) PAX \& X-133/FrothPro 630 and PAX \& X-133

2) PAX \& X-133/FrothPro 630 and Aero $3501 \& X-133$

3) PAX \& X-133/FrothPro 630 and Aero $249 \& X-133$

4) PAX \& X-133/FrothPro 630 and SEX \& X-133/FrothPro 618

5) PAX \& X-133/FrothPro 630 and Aero $249 \& X-133 /$ FrothPro 618

6) PAX \& X-133/FrothPro 630 and Aero $3510 \& X-133 /$ FrothPro 630

7) PAX \& X-133/FrothPro 630 and Aero $249 \& X-133 /$ FrothPro 630

8) PAX \& X-133/FrothPro 630 and SEX \& X-133/FrothPro 706

9) PAX \& X-133/FrothPro 630 and Aero $3510 \& X-133 /$ FrothPro 706

10) PAX \& X-133/FrothPro 630 and Aero $249 \& X-133 /$ FrothPro 706

11) PAX \& $X-133 /$ FrothPro 706 and PAX \& $X-133$

12) PAX \& X-133/FrothPro 706 and Aero $249 \& X-133$

13) PAX \& X-133/FrothPro 706 and SEX \& FrothPro 618

14) PAX \& X-133/FrothPro 706 and Aero $249 \&$ FrothPro 618

15) PAX \& X-133/FrothPro 706 and Aero $3501 \& X-133 / F r o t h P r o ~ 630$

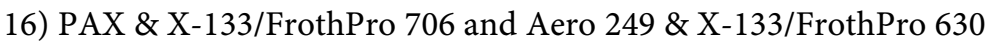

17) PAX \& X-133/FrothPro 706 and SEX \& X-133/FrothPro 706

18) PAX \& X-133/FrothPro 706 and Aero $3501 \& X-133 /$ FrothPro 706

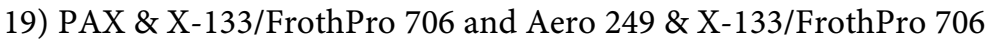

The test that resulted in the highest copper recovery is PAX \& X-133/FrothPro 630. As mentioned earlier, the baseline (SEX and X-133) is currently used in the operation in question; thus, we would like to know the confidence level of the difference in copper recovery between the test with the highest copper recovery and the baseline. Thus, the Fisher Least Squared at the $90 \%$ confidence level was performed.

If a $90 \%$ confidence level is considered.

$$
\mathrm{LSD}=t_{0.05,16} \sqrt{\frac{2 \times 2.86}{2}}
$$


where $t_{0.05,16}=1.746$

$$
\mathrm{LSD}=2.95
$$

The difference between the copper recovery of the baseline (SEX and X 133) and PAX \& X-133/FrothPro 630 has to be at least 2.95\%. The test with PAX \& $\mathrm{X}-133$ /FrothPro 630 resulted in a copper difference of $3.44 \%$. Therefore, the copper recovery increase between the conditions PAX \& X-133/FrothPro 630 and SEX \&X-133 is $3.44 \%$ at the $90 \%$ confidence level.

In order to confirm at which particle ranges the recovery increased, a size-by-size mineralogical analysis on the tails was done as well as a size by size recovery. The mass pull for these tests was low; thus, obtaining enough concentrate sample for mineralogy was not possible.

Figure 12 shows the \%mass of chalcopyrite in the tails for the baseline and PAX \& X-133/FrothPro 630. The condition with PAX \& X-133/FrothPro 630 was chosen for mineralogy since it has the highest copper recovery improvement relative to the baseline. The biggest gains in chalcopyrite recovery are obtained in the $+150-212 \mu \mathrm{m}$ and $-25 \mu \mathrm{m}$ size fractions (dotted circles).

Figure 13 illustrates the estimated chalcopyrite recovery as a function of

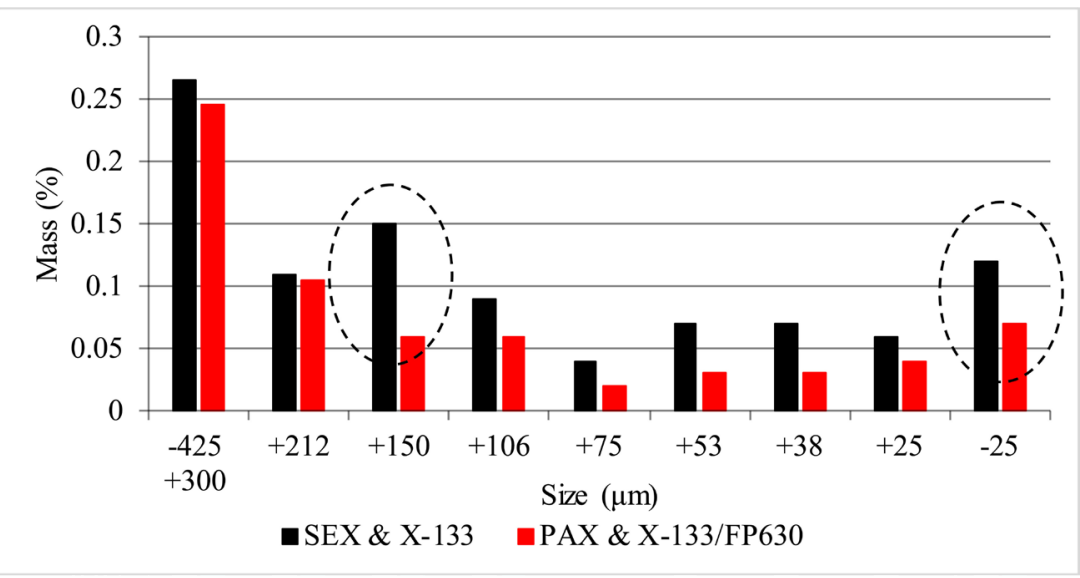

Figure 12. Chalcopyrite mass (\%) versus particle size in the flotation tails.

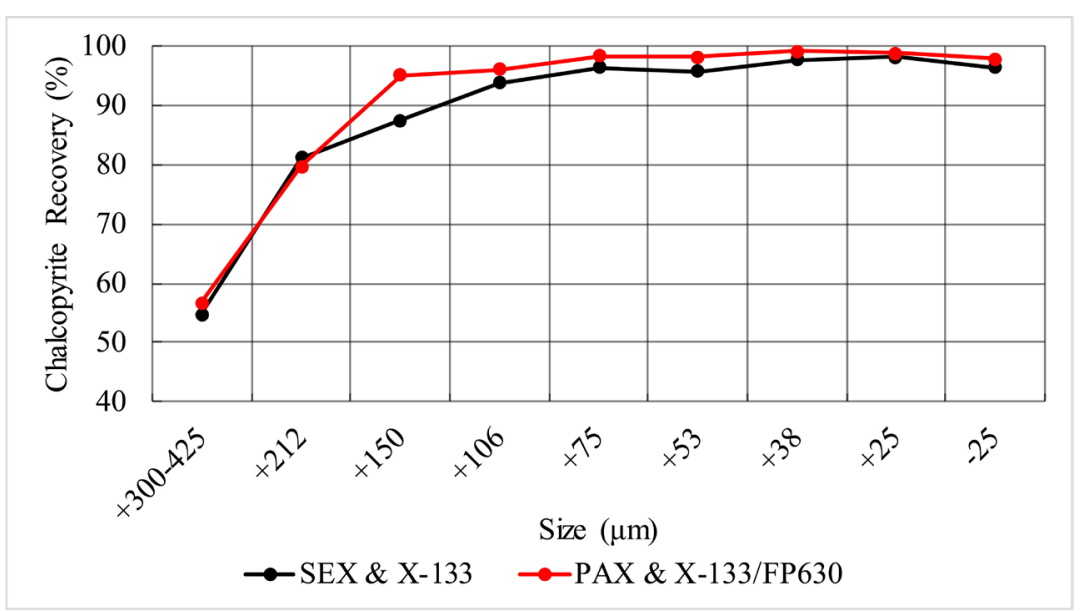

Figure 13. Estimated chalcopyrite recovery as a function of particle size. 
size-by-size for SEX \& X-133 and PAX \& X-133/FrothPro 630. The size-by-size copper recovery was calculated by subtracting the amount of chalcopyrite in the feed and tails. The raw size-by-size copper recovery data (there was not enough mass in the concentrates to perform data reconciliation) showed that higher copper recovery was achieved at $150 \mu \mathrm{m}$ for the test conducted with SEX \& PAX \& X-133/FrothPro 630 compared to that obtained with the baseline. Thus, at sizes $212 \mu \mathrm{m}$ and higher, conventional flotation was not effective at recovering coarse particles regardless of the reagents used.

Table 12 shows the ANOVA for the molybdenum recovery. The effects of the collectors and frothers are not significant since the $\mathrm{F}_{\mathrm{o}}$ parameters are not greater than the $f$ critical parameters ( $95 \%$ confidence level) for the collectors, frothers and interaction between the collectors and frothers.

Figure 14 shows the normality plot for the molybdenum recovery residuals. The residuals follow the normality line; thus, they are normal and satisfy the normality requirement for the ANOVA analysis.

Figure 15 illustrates the residuals (molybdenum recovery) versus fitted molybdenum recovery. There is no trend or tendency in this figure; therefore, the variance is constant.

Figure 16 and Figure 17 show the molybdenum recovery versus run order and residuals (molybdenum recovery) versus run order, respectively. These

Table 12. Analysis of variance for molybdenum recovery (\%).

\begin{tabular}{cccccccc}
\hline $\begin{array}{c}\text { Source of } \\
\text { Variation }\end{array}$ & $\begin{array}{c}\text { Sum of } \\
\text { Squares }\end{array}$ & $\begin{array}{c}\text { Degrees of } \\
\text { Freedom }\end{array}$ & $\begin{array}{c}\text { Mean } \\
\text { Square }\end{array}$ & Fo & $\mathbf{f}_{\text {critical }}$ & P value & Significant \\
\hline Collector & 30.44 & 3 & 10.15 & 0.67 & 3.24 & 0.583 & No \\
Frother & 44.24 & 3 & 14.75 & 0.97 & 3.24 & 0.431 & No \\
Interaction & 221.94 & 9 & 24.66 & 1.63 & 2.54 & 0.189 & No \\
Error & 242.78 & 16 & 15.17 & & & & \\
Total & 539.41 & & & & & &
\end{tabular}

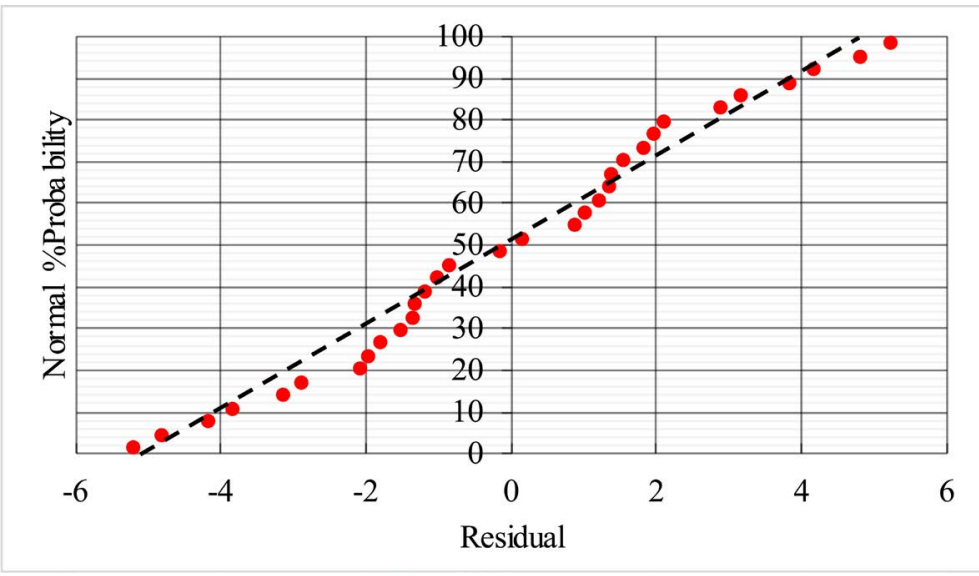

Figure 14. Normal\% probability versus residuals for molybdenum recovery. 


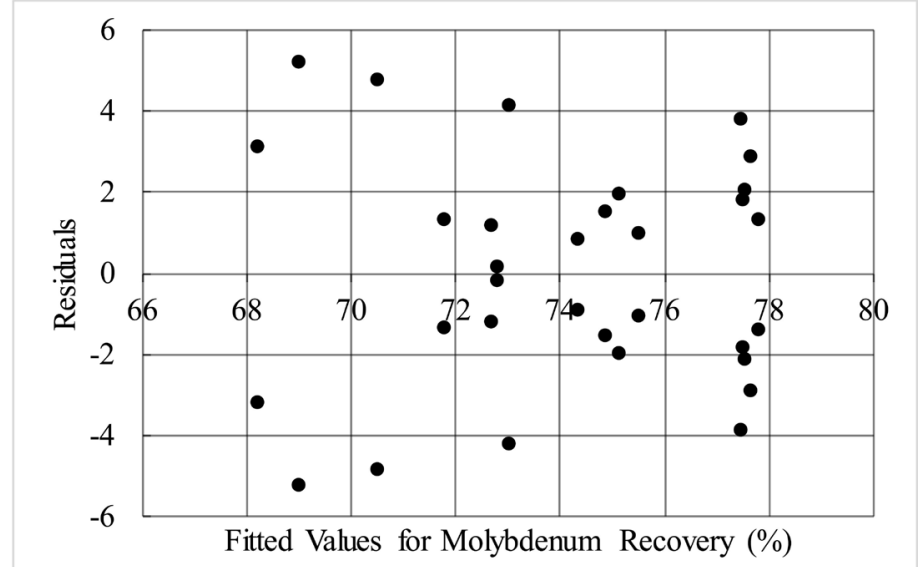

Figure 15. Residuals (molybdenum recovery) versus fitted molybdenum recovery.

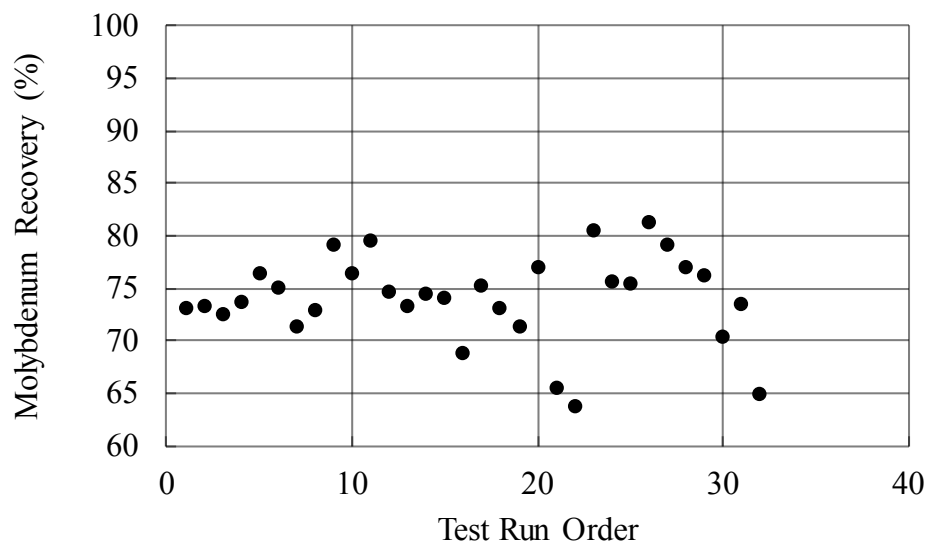

Figure 16. Molybdenum recovery versus test run order.

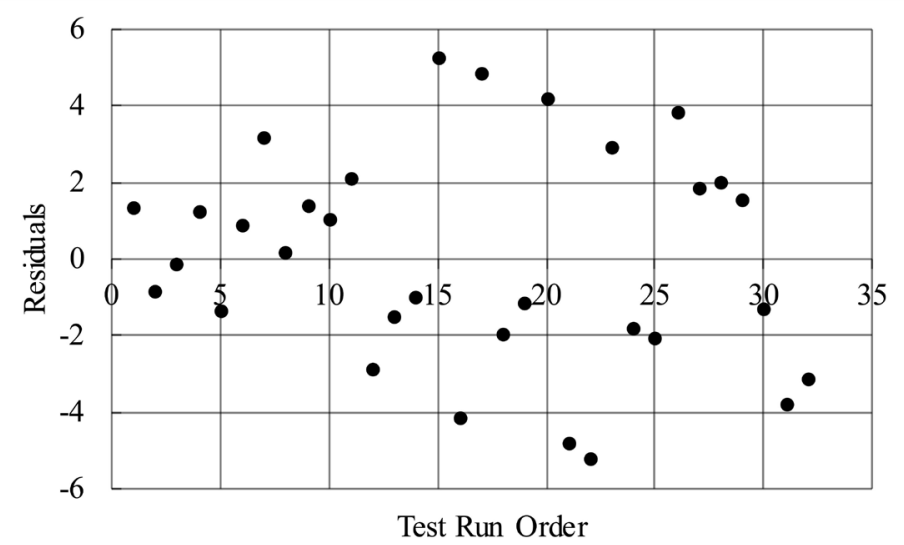

Figure 17. Residuals (molybdenum recovery) versus test run order.

graphs should be scattered or there should not be any trend. If there was a trend, then the data would be biased or an undesirable event could have happened, thus, influencing the data. There are no trends. Therefore, this requirement is met. All the requirements of the molybdenum recovery are met, thus, the ANOVA conclusions are reliable. 


\section{Discussion}

The improvements made with PAX and X-133/FrothPro 630 were confirmed using statistical analysis. This approach should be used with all testing conducted in metallurgy. Therefore, the metallurgist and management can make important decisions with a good level of confidence.

The testwork shows that both a stronger collector and frother (higher glycol concentration) are required for coarse particle recovery. The stronger collector for higher hydrophobicity of the recoverable mineral and a stronger frother to support the coarser particles in the froth phase.

In the plant there are other factors that need to be considered. If large flotation cells are used, for example, $300 \mathrm{~m}^{3}$, then the operator has to ensure that enough frother is added to have a stable froth. Also, froth crowders may be considered to reduce the residence time of the particles in the froth phase before entering the launders. Reducing this time will reduce particle drop back to the pulp phase.

\section{Conclusions}

- The Analysis of Variance (ANOVA) analysis was used to establish whether the effects of the collectors and frothers on copper and molybdenum recoveries were significant. All the requirements of the ANOVA methodology were met; thus, the conclusions derived from the ANOVA analysis are reliable.

- The condition with PAX \& X-133/FrothPro 630 resulted in the highest copper recovery gain relative to the baseline (SEX \& X-133). The copper recovery gain was approximately $3 \%$.

- The collectors and frothers did not have a significant effect on molybdenum recovery.

\section{Acknowledgements}

The authors are grateful for the good laboratory testwork performed by Raymond Chevrier. The contribution of the Canmet Mining Analytical Services Group is gratefully acknowledged.

\section{Conflicts of Interest}

The authors declare no conflicts of interest regarding the publication of this paper.

\section{References}

[1] Jameson, G.J. (2010) Advances in Fine and Coarse Particle Flotation. Canadian Metallurgical Quarterly, 49, 325-3320. https://doi.org/10.1179/cmq.2010.49.4.325

[2] Mehfert, P.J. (2017) Investigating the Potential of HydroFloat ${ }^{\mathrm{TM}}$ Coarse Particle Flotation Techniques on Copper Sulphide Ores. 49th Annual Canadian Mineral Processors, Ottawa, 17-19 January 2017.

[3] Fosu, S., Skinner, W. and Zanin, M. (2015) Detachment of Coarse Composite 
Sphalerite Particles from Bubbles in Flotation: Influence of Xanthate Collector Type and Concentration. Minerals Engineering, 71, 73-84.

https://doi.org/10.1016/j.mineng.2014.10.014

[4] Trahar, W.J. (1981) A Rational Interpretation of the Role of Particle Size in Flotation. International Journal of Mineral Processing, 8, 289-327.

https://doi.org/10.1016/0301-7516(81)90019-3

[5] Crawford, R. and Ralston, J. (1988) The Influence of Particle Size and Contact Angle in Mineral Flotation. International Journal of Mineral Processing, 23, 1-24. https://doi.org/10.1016/0301-7516(88)90002-6

[6] Newcombe, B., Bradshaw, D. and Wightman, E. (2012) Flash Flotation....and the Plight of the Coarse Particle. Minerals Engineering, 34, 1-10.

https://doi.org/10.1016/j.mineng.2012.03.023

[7] Ata, S. and Jameson, G.J. (2013) Recovery of Coarse Particles in the Froth Phase-A Case Study. Minerals Engineering, 45, 121-127.

https://doi.org/10.1016/j.mineng.2013.02.006

[8] Boulton, A., Fornasiero, D. and Ralston, J. (2003) Characterization of Sphalerite and Pyrite Flotation Samples by XPS and Tof-SIMS. International Journal of Mineral Processing, 70, 205-219. https://doi.org/10.1016/S0301-7516(03)00003-6

[9] Korkmaz, M.E. and Günay, M. (2018) Finite Element Modelling of Cutting Forces and Power Consumption in Tuning of AISI 420 Martensitic Stainless Steel. Arabian Journal for Science and Engineering, 43, 4863-4870. https://doi.org/10.1007/s13369-018-3204-4

[10] Napier-Munn, T.J. (1995) Detecting Performance Improvements in Trials with Time-Varying Mineral Processes-Three Case Studies. Minerals Engineering, 8, 843-858. https://doi.org/10.1016/0892-6875(95)00047-T

[11] Montgomery, D.C. (2013) Design and Analysis of Experiments. Eight Edition, John Wiley \& Sons Inc., Hoboken. 